\title{
Study of Prevalence of Metabolic Syndrome in Offspring of Type 2 Diabetic Population
}

\author{
Samreen Begum 1 , Gosangari Suchitra ${ }^{2}$, Akshay Berad ${ }^{3}$ \\ ${ }^{1}$ Resident, Dept. of Physiology, Osmania Medical College, Hyderabad, TS, ${ }^{2}$ Assistant Professor, Dept. of \\ Physiology, RIMS, Adilabad, TS, ${ }^{3}$ Associate Professor, Dept. of Physiology, RIMS, Adilabad, TS
}

\begin{abstract}
Metabolic Syndrome is defined as Syndrome $\mathrm{X}$ is a cluster of co-existing metabolic abnormalities like obesity, hypertension and dyslipidemia leading to a marked increase in

Diabetes mellitus and a five fold increase in CVD thereby imposing a great burden on public health and clinical practice. Metabolic syndrome encompasses a set of conditions of which obesity in particular visceral obesity, is an important component. Obesity has a positive correlation with incidence and severity of diabetes. Aim of the study is to estimate the prevalence of Metabolic syndrome in offspring of Type 2 diabetic population. This study was conducted to estimate the prevalence of metabolic syndrome and its components in offsprings of type 2 diabetes Mellitus population and it includes 100 subjects who were diabetic and presenting to Osmania General Hospital, Hyderabad. Offspring of type II diabetes parents exhibits higher prevalence of metabolic syndrome . Normoglycemic offspring exhibits higher prevalence of hypertriglyceridemia indicating precedence of lipid abnormalities to glucose intolerance. Diabetic offspring have a statistically significant prevalence of metabolic syndrome than the non diabetic offspring.
\end{abstract}

Keywords: Metabolic syndrome, Offspring, Diabetes.

\section{Introduction}

Metabolic Syndrome,originally defined as Syndrome X in 1988 by Gerald Reaven, is a cluster of co-existing metabolic abnormalities like obesity, hypertension and dyslipidemia leading to a marked increase in Diabetes mellitus and a five fold increase in CVD thereby imposing a great burden on public health and clinical practice. Metabolic syndrome encompasses a set of conditions of which obesity in particular visceral obesity, is an important component. Obesity has a positive correlation with incidence and severity of diabetes. Diabetes mellitus is a syndrome characterized by chronic

\footnotetext{
Corresponding Author: Dr. Gosangari Suchitra

Assistant Professor, Dept. of Physiology, RIMS, Adilabad, TS

e-mail: suchithra66@gamail.com
}

hyperglycemia and disturbances of carbohydrate, fat and protein metabolism associated with absolute or relative deficiencies in insulin secretion and/or insulin action. The clinical class of diabetes mellitus is divided mainly into 2 groups, IDDM - TYPE 1 DIABETES and NIDDM-TYPE 2 DIABETES. Type-2 diabetes accounts for over $(90 \%)$ of diabetes worldwide and is associated with enormous amount of morbidity and mortality resulting from its microvascular, macrovascular and neuropathic complications ${ }^{[1]}$. Components of metabolic syndrome constitute a particular combination of what ATPIII terms underlying, major and emerging risk factors. According to ATPIII, underlying risk factors for CVD are obesity (especially abdominal obesity), physical inactivity, and atherogenic diet. Type 2 diabetes is a heterogeneous disorder associated with absolute or relative deficiencies in insulin Secretion and/ or insulin action. Both genetic as well as environmental factors contribute to its development. There are multiple sites for insulin resistance ${ }^{[2]}$. The most important site of insulin resistance in Type 2 diabetes is in the 
muscle followed by liver. Insulin resistance and $\beta$-cell dysfunction are necessary for the development of frank diabetes although the relative contribution may vary in different individuals and that mild hyperglycemia once developed, has deleterious effect upon both insulin secretion and insulin sensitivity ${ }^{[3]}$. Steven M. Haffneret $a l$, demonstrated increased insulin concentrations (both in fasting state and after OGTT) in the non-diabetic offspring of diabetic parents, when compared with nondiabetic offspring of nondiabetic parents and supported the insulin resistance hypothesis ${ }^{[4]}$. Johan Eriksson et al concluded in their study that both insulin resistance and impaired insulin secretion are necessary for the development of impaired glucose tolerance ${ }^{[5]}$. (Insulin resistance with respect to lipolysis in the offspring of diabetic parents has been studied in a limited number of published studies).Aim of the study is to estimate the prevalence of Metabolic syndrome in offspring of Type 2 diabetic population.

\section{Materials and Method}

The study population compromised the children of diabetic population, who have been attending diabetic Clinic of Osmania General Hospital, Hyderabad, Most of them belongs to middle socioeconomic group.

The Data for this study was collected from 100 normoglycemic individuals of diabetic parents.

Sample Size : 100

Study Design : Non Randomized study

Duration of study : 2 years

The subjects were selected randomly after fulfilling the following

\section{Inclusion Criteria:}

1. Age of the subject to be tested should be more than 30 years.

2. Mother or father or both of the subjects parent should be a diabetic patient. (The duration of the illness or the nature of therapy being received, by the patient is not taken into account).

3. Subject should not be a known diabetic.

\section{Exclusion Criteria:}

1. Patient with type 2 diabetes

2. Age $<30 \mathrm{yrs}$.
3. Pregnant women

4. Patients diagnosed as hypothyroid, hyperthyroid, nephritic syndrome, liver diseases, on OCP's

5. Patients with gestational diabetes patients and familialdyslipidemia.

After explaining the purpose of the study, the subject came forward voluntarily for undergoing the tests. A total 100 eligible subjects were enrolled in the study. The subjects were instructed to have their usual diet with avoidance of high calorie and high fat diet for the 3 days preceding the study.

\section{Investigation:}

\section{Glucose Tolerance Test}

Fasting Lipid Profile: On the day of the test, subjects were advised to attend the Dept. of Endocrinology at 8 A.M. after an overnight fast (10-12 hours). A fasting sample of venous blood was taken for estimation of plasma glucose and lipid profile. Then $75 \mathrm{gm}$. of glucose was given orally in $200-300 \mathrm{ml}$ of water and venous blood samples were collected after one hour and two hours . During the time between sampling the subjects were advised to rest and not to smoke. During this time height, weight, waist \& hip circumference, Blood pressure were recorded. Height, weight, BMI, waist and hip circumference was taken.

Analysis of Data: The data thus obtained was tabulated and represented in figures. Subjects were studied after sub-classifying them into different groups for comparison of important variables. Data collected for the study was analysed statistically. Descriptive statistical analysis has been carried out in the present study. Results on continuous measurements are presented as Mean \pm SD (Min-Max) and results on categorical measurements are presented in Number (\%). Significance is assessed at $5 \%$ level of significance. $Z$ test for proportion has been used to find the significant incidence of metabolic syndrome with study characteristics. Student test has been used to find the significance of parameterson continuous scale between controls and cases.

\section{Significant figures:}

+ Suggestive significance $\mathrm{P}<0.10$

* Moderately significant $\mathrm{P}<0.05$.

** Strongly significant $\mathrm{P}<0.01$. 


\section{Results}

Out of 100 subjects $54 \%$ were males and $46 \%$ were females.

Maximum number of subjects was in the age group of 33 to 39 years and minimum were in the age group of
$35-40$ years.

Out of 100 subjects, $79 \%$ of the study subjects were normoglycemic, $12 \%$ were having impaired Glucose levels and $9 \%$ were denovo diabetic

Table 1: Prevalence of Hypertension in Study Population

\begin{tabular}{|l|c|c|c|}
\hline Category & NGT & IGT & Diabetic \\
\hline Number of individuals & 2 & 10 & 20 \\
\hline
\end{tabular}

Table 1 shows prevalence of Hypertension was found to be more in diabetic offspring.

Table 2: Components of Metabolic Syndrome in NGT Subjects

\begin{tabular}{|l|c|c|}
\hline Components & Number of Subjects & Percentage \\
\hline Hypertriglyceridaemia $(\geq 200 \mathrm{mg} / \mathrm{dl})$ & 18 & $22.66 \%$ \\
\hline Low HDL - Cholesterol $(\leq 35 \mathrm{mg} / \mathrm{dl})$ & 7 & $6.32 \%$ \\
\hline High Cholesterol $(\geq 240 \mathrm{mg} / \mathrm{dl})$ & 15 & $18.9 \%$ \\
\hline High LDL- Cholesterol $(\geq 160 \mathrm{mg} / \mathrm{dl})$ & 13 & $16.45 \%$ \\
\hline
\end{tabular}

Table 3 : Components of Metabolic Syndrome in IGT Population

\begin{tabular}{|l|c|c|}
\hline Components & Number & Percentage \\
\hline Hypertriglyceridemia & 2 & $16.66 \%$ \\
\hline Low HDL & 2 & $16.66 \%$ \\
\hline High Cholesterol & 3 & $25 \%$ \\
\hline High Ldl & 4 & $33.3 \%$ \\
\hline
\end{tabular}

Table 4 : Components of Metabolic Syndrome in Diabetic Offspring

\begin{tabular}{|l|c|c|}
\hline Components & Number & Percentage \\
\hline Hypertriglyceridemia & 4 & $44.4 \%$ \\
\hline Low HDL & 1 & $11.1 \%$ \\
\hline High Cholesterol & 3 & $33.3 \%$ \\
\hline High LDL & 2 & $28.2 \%$ \\
\hline
\end{tabular}

Table number 2,3,4 shows the components of metabolic syndrome in normoglycemic, impaired Glucose tolerant and diabetic subjects .

Table 5: Prevalence of Metabolic Syndrome in Study Population

\begin{tabular}{|l|c|c|}
\hline \multirow{2}{*}{ Group } & Metabolic & Metabolic \\
\cline { 2 - 3 } & Syndrome (Present) & Syndrome (Absent) \\
\hline Non Diabetic & $26 \%$ & $74 \%$ \\
\hline Offsprings & & \\
\hline Diabetic Offspring & $70 \%$ & $30 \%$ \\
\hline
\end{tabular}

Table 5 shows that $70 \%$ diabetic offspring subjects had metabolic syndrome . 
Table 6: Association of risk factors in study population

\begin{tabular}{|c|c|c|c|c|}
\hline Risk Factor & $\begin{array}{c}\text { Total Number of } \\
\text { subjects }\end{array}$ & $\begin{array}{c}\text { Subjects with } \\
\text { metabolic syndrome }\end{array}$ & $\%$ & $P$ value \\
\hline Number of patients studied & 100 & 26 & 26 & - \\
\hline Age $>50 y r s$ & 32 & 12 & 37.5 & 0.138 \\
\hline Male & 54 & 14 & 26 & 0.917 \\
\hline Female & 46 & 11 & 25 & 0.911 \\
\hline Dyslipidemia & 74 & 74 & 100 & $<0.001 * *$ \\
\hline $\mathrm{BMI}>25 \mathrm{~kg} / \mathrm{m} 2$ & 58 & 16 & 27 & 0.844 \\
\hline Waist & 30 & 26 & 86.7 & $<0.001 * *$ \\
\hline \multicolumn{5}{|l|}{ Circumference } \\
\hline Triglycerides & 35 & 35 & 100 & $<0.001 * *$ \\
\hline \multicolumn{5}{|l|}{$>150 \mathrm{mg} / \mathrm{dl}$} \\
\hline $\mathrm{HDL}<40 \mathrm{mg} / \mathrm{dl}$ & 27 & 18 & 66.7 & $<0.01^{*}$ \\
\hline $\mathrm{LDL}>100 \mathrm{mg} / \mathrm{dl}$ & 24 & 24 & 100 & $<0.001 * *$ \\
\hline $\mathrm{BP}>130 / 85 \mathrm{mmHg}$ & 32 & 26 & 81 & $<0.001 * *$ \\
\hline OGTT & 21 & 21 & 100 & $<0.001 * *$ \\
\hline
\end{tabular}

*Moderately significant $\mathrm{P}<0.05$., **Strongly significant $\mathrm{P}<0.01$.

\section{Discussion}

Type 2 diabetes results from environmental and genetic factors. The Concordance rate for Type 2 diabetes between identical twins is $60-90 \%$. Further, type 2 develops as a result of both $\beta$-Cell defect and insulin resistance. This is more often associated with other components of "metabolic syndrome" (the so-called SYNDROME-X). Thus, hypertension, dyslipidaemia, central obesity, are often seen in type-II diabetic patients. Thus type 2 diabetes may be viewed as one of the components of "metabolic syndrome". Maximum number of subjects were in the Age group of 35-45 years. There was $54 \%$ males and $46 \%$ females $79 \%$ of the study subjects were normoglycemic, $12 \%$ were having impaired glucose tolerance and $9 \%$ were detected Denovo Type 2 Diabetic. The study done by Earl S. Ford et al and Louis Guize et al also shows the increasing prevalence of metabolic syndrome with age and it also shows that the prevalence was found more in males than in females. In this Study, the prevalence of IGT and diabetes in offsprings of type 2 diabetic population was found to be $12 \%$ and $9 \%$ respectively. In India, there are about 69.2 million people with diabetes and are expected to cross 123.5 million by $2040^{[6]}$. A prevalence of $9 \%$ in the study is much higher than the overall prevalence, for the simple reason that the study population belongs to high risk category in the sense that they are all children of diabetic parents. Although intensive glycemic control lowers the incidence and progression of microvascular complications, the morbidity associated with these complications is still increasing. ${ }^{[7]}$. In this study, the prevalence of Metabolic Syndrome in diabetic subjects was found to be high i.e, $70 \%$, which is statistically significant $(\mathrm{P}<0.001)$ and 6.64 times more when compared to non-diabetic subjects . The study done by Peter. W.F etal showed that in men, with the metabolic syndrome the relative risk(RR) were $\mathrm{RR}=2.88$ for $\mathrm{CVD}$, $\mathrm{RR}=2.54$ for $\mathrm{CHD}$ and $\mathrm{RR}=6.92$ for $\mathrm{T} 2 \mathrm{DM}$ and $\mathrm{RR}$ ' $\mathrm{s}$ were lower in women for CVD $(\mathrm{RR}=2.25)$ and $\mathrm{CHD}$ $(R R=1.54)$ but they were similar for $T 2 D M(R R=6.90)$ ${ }^{[8]}$. When the risk for new onset diabetes was examined for the Framingham cohort in both men and women, the presence of metabolic syndrome was highly predictive of new-onset diabetes. The study done by Patricia Blackburn et al in 2007 shows that the prevalence of CAD reached $43 \%$ in type 2 diabetic women and $31 \%$ in non-diabetic women. Thus it provides the evidence that diabetes is a heterogeneous condition and diabetic subjects characterised by the metabolic syndrome were at substantially higher risk for coronary heart disease (CHD). Hypertension was found to be more prevalent 
in diabetic subjects with metabolic syndrome i.e, $70 \%$, whereas in non-diabetic subjects with metabolic syndrome, it was found to be less prevalent i.e, only $26 \%$. History of dyslipidemia was found to be $100 \%$ in non-diabetic offsprings. The raised triglyceride levels in subjects with metabolic syndrome was found to have in all $100 \%$ subjects, indicating that highertriglyceride levels in diabetic subjects with metabolic syndrome was statistically significant and positively associated with incidence of metabolic syndrome. Individuals with metabolic syndrome are at increased risk for CHD. The study done by Hanna-Maaria Lakka et al in Finland shows that the highest risk (3.0-4.3- fold) associated with metabolic syndrome was forCHD mortality. Risk attenuated progressively for cardiovascular and overall mortality, indicating that the impact on overall mortality was mediated mainly by CVD mortality $\mathrm{CHD}^{[9]}$. The study done by Jianjun Wang et al Finland shows that the metabolic syndrome was associated with a statistically significant risk for CVD mortality (Hazard Ratios, HR's from 1.31 to 1.51 ) and CHD mortality (HR's from 1.42 to 1.58).41. When the data regarding the lipid levels is analysed, it has been found that all the three categories (NGI, IGT and Diabetes) showed various lipid abnormalities. The BMI of $\geq 25 \mathrm{~kg} / \mathrm{m} 2$ was found in $27 \%$ of non-diabetic offsprings with metabolic syndrome. It indicates that higher BMI is positively associated with metabolic syndrome in subjects. Metabolic Syndrome in our population is quite prevalent in both diabetic and non-diabetic groups. A simple measurement of waist circumference $\&$ or BMI which can be done at any clinic or peripheral health care level can identify a patient at risk for metabolic syndrome. In this study, a strong parent-offspring association for MetS between Indian adolescents and their parents were found. Asians develop the adverse consequences of obesity at lower BMIs and lower cutoffs are used to define obesity in Asian adults ${ }^{[10]}$. The Bogalusa Heart Study identified that childhood parental history of type 2 diabetes, along with adiposity, glucose and lipoprotein variables, were associated with an increased risk of diabetes in adulthood $^{[11]}$. The strong parent-offspring association could be due to hereditary or environmental factors. It is widely recognized that genetic and environmental factors both contribute to the development of $\mathrm{MetS}^{[12]}$.

\section{Conclusion}

Offspring of type II diabetes parents exhibits higher prevalence of metabolic syndrome. Normoglycemic offspring exhibits higher prevalence of hypertriglyceridemia indicating precedence of lipid abnormalities to glucose intolerance. Diabetic offspring have a statistically significant prevalence of metabolic syndrome than the non diabetic offspring. Prevalence of metabolic syndrome increases with worsening glucose tolerance, as reflected by high OGTT levels. Hypertension was found to be more prevalent in diabetic offspring with metabolic syndrome. In the diabetic offspring with metabolic syndrome all had raised triglyceride \& LDL levels which was statistically significant and positively associated with the prevalence of metabolic syndrome. In the non-diabetic offspring with metabolic syndrome, raised LDL \& low HDL was present in all subjects. Higher BMI is positively associated with metabolic syndrome in subjects with diabetes but not in nondiabetics. All findings reveal the offsprings of diabetic population is at a high risk for metabolic syndrome. Intensive life style modifications along with therapies for different risk factors can prevent the progression to diabetes and atherosclerotic cardiovascular disease in high risk population.

Ethical Clearance: Taken from Institutional ethical committee.

\section{Source of Funding: Self .}

\section{Conflict of Interest: None.}

\section{References}

1. Orasanu G, Plutzky J. The pathologic continuum of diabetic vascular disease. J Am Coll Cardiol. 2009;53(5 Suppl):S35-42. [PMC free article] [PubMed] [Google Scholar]

2. Groop LC et al - Glucose and FFA metabolism in NIDDM - Evidence for multiple sites of insulin resistance J. Clin. investigation (1989) 84; 205-13.

3. Leahy JL., et al - Beta cell dysfunction induced by chronichyperglycaemia - Diabetes Care (1992); $15 ; 442-55$.

4. Steven M. Haffner et al - Increased insulin concentration in nondiabetes offspring of diabetic parents - NEJM (1988) 319; 1279 -301.

5. Johan Erikson et al - Early metabolic defects in persons atincreased risk for NIDDM, NEJM (1989) $321 ; 337-43$.

6. International Diabetes Federation. IDF Atlas. 7th edition. [Last accessed on 2015 Dec 27]. Available from: http://www.diabetesatlas.org . 
7. Advance Collaborative Group. Patel A, MacMahon S, Chalmers J, Neal B, Billot L, et al. Intensive blood glucose control and vascular outcomes in patients with type 2 diabetes. N Engl J Med. 2008;358:2560-72. [PubMed] [Google Scholar].

8. Peter W.F Wilson Ralph B.D“ Agostino, Helen parise, Lisa Sullivan, James B. Meiges. Metabolic syndrome as a precursor of Cardiovascular Disease and Type 2 Diabetes Mellitus. Circulation. 2005;112:3066-3072.

9. Human-Maaria Lakka, David E. Laaksonen, Timo A Lakka, Leo k. Niskanen, Esko Kumpulso. The Metabolic syndrome and Total and cardiovascular Disease Mortality in Middle aged Men. JAMA. 2002; 288:2709-2716.
10. Tan CE, Ma S, Wai D, Chew SKTaiES. Can we apply the National Cholesterol Education Program Adult Treatment Panel definition of the metabolic syndrome to Asians? Diabetes Care 2004;27:11821186 pmid: 15111542.

11. Nguyen QM, Srinivasan SR, Xu JH, Chen W, Berenson GS. Influence of childhood parental history of type 2 diabetes on the pre-diabetic and diabetic status in adulthood: the Bogalusa HeartStudy. Eur J Epidemiol 2009;24:537-539 pmid:19618280.

12. Loos RJ, Katzmarzyk PT, Rao DC, et al; Heritage Family Study. Genome-wide linkage scan for the metabolic syndrome inthe HERITAGE Family Study. J Clin Endocrinol Metab 2003;88:5935-5943 pmid:14671193. 